\title{
Methodological Approaches To The Study Of Semiotics Of Sound, In The Context Of Creating Educational Audio-Visual Material
}

\author{
${ }^{1}$ Stanislav Markov, ${ }^{2}$ Ivan Reshetnikov \\ ${ }^{1} \mathrm{PhD}$ student, State Institute of Arts and Culture of Uzbekistan, Tashkent, Uzbekistan. \\ ${ }^{2}$ Senior Scientist in the Information and Mathematical Department of the Center for the Study of Public Opinion "IzhtimoiyFikr", \\ Uzbekistan.
}

\begin{abstract}
This article discusses the possibilities of using the methods of semiotics of sound in creating educational audio-visual material. Authors, based on the results of the study, offer methodological approaches to the study of the relationship of sound and image at the level of emotional perception
\end{abstract}

Keywords:

semiotics of sound, video lessons, emotional perception, pedagogical technologies, audio-visual content

Article Received: 18 October 2020, Revised: 3 November 2020, Accepted: 24 December 2020

\section{Introduction}

The development of modern technologies and the widespread informatization of society have led to the need of creation of new educational technologies, like conducting video lessons.

If earlier video lessons were just one of the interactive educational technologies methods, now video lessons gradually become full-fledged technologies that replace classical technologies because of informatization of society and modern trends that strengthen the role of distance learning.

The particular relevance of applying these technologies is due to the pace of development of the world of media and increasing the number of different online courses.

\section{Materials and methods}

It doesn't matter what specialty a person has, whether it is acting lessons, or a course in social psychology, it has historically developed that video content is the basis of online courses. Video courses and lessons have several advantages:

firstly, video synthesizes various types of visualization: auditory, visual, linguisticsituational, subjective and figurative. In practice, you can watch, listen or read a video (if you have subtitles that are easy to make), which creates the basis for individual training of audiles, visuals and kinesthetic;

secondly, with the auditory perception of a speech message, facial expressions, gestures, body movements, personal, external demonstration of participants, socially significant information are simultaneously visually perceived. According to psychological studies, non-verbal, paralinguistic phenomena transmit up to $40 \%$ of information. The text doesn't have these opportunities;

- thirdly, the video has a greater emotional impact than the text. It causes positive feelings among students, increases their motivation, especially when the audio is picked up correctly for the video content $[1, \mathrm{p} .46]$.

Let's look at details of the issues of perception, because emotional perception in essence is a process of communicative communication in the author-consumer system. For us it's important to define the following key concepts:

-emotions - is a group of psychophysiological characteristics which represent an internal, subjective experience of the mental and physiological states of a person, 
accompanied by various feelings. Emotions express an estimated attitude to individual conditions that contribute or impede the implementation of human life[2];

-perception - is a holistic reflection of objects, situations and events that occurs with the direct impact of physical stimuli on the receptor surfaces of the senses. Along with the processes of sensation, perception provides a direct-sensory orientation in the surrounding world [3].

Based on these definitions above, we will consider emotional perception as a holistic mechanism that is influenced by a number of different factors, At the same time we will try to abstract from the subjectification of the emotional spectrum as much as possible. We will consider only the general direction of emotional perception as reactions to the communicative process between the author of a work and the consumer of audiovisual content in the framework of objective reality. However, we will place particular emphasis on the perception of precisely audio content and its impact on the overall concept of audiovisual material. And to do so we will rely on the results of a scientific experiment conducted as part of the dissertation work related to the study of the semiotics of sound.

The main goal of the experiment was to identify the basic laws of semiotics of sound as a sign system for the perception of audiovisual content. The participants of the experiment were shown four audio / video fragments in the following order: the original video image without sound; original sound without video image; original image with original sound; the original image with a modified sound.

The experiment was carried out using a combination of survey and observation methods, with the participation of 100 respondents, who were divided into 4 groups:

- group \#1 (control) did not receive information about the script and the author's idea and the basic principles of semiotics and semiotics of sound were not explained;
- group \#2 - received information about the script and the author's idea;

- group \#3 - did not receive information about the script and the author's idea of the work, but the basic principles of semiotics and semiotics of sound were explained;

- group \#4 - received information about the script and the author's idea, and the basic principles of semiotics and semiotics of sound were explained.

\section{Result and discussion}

To ensure representativeness at an acceptable level, the number of experiment participants would need to be slightly larger than 100. However, in accordance with the provisions of statistical theory, representativeness is understood as an acceptable degree of difference between the average value of some key parameter in the sample and the general population called accuracy, with an acceptable degree of probability such a distinction called reliability. The distribution of values of the key parameter should have a normal form [4, p.104], which we can observe in the example of the Diagram \# 1. Based on this, the implemented sample should be considered conditionally representative and conclude that the technology for selecting respondents was not violated.

Diagram 1

Cross-frequency distribution of respondents' reactions to the demonstration of the original video image without sound in four groups 


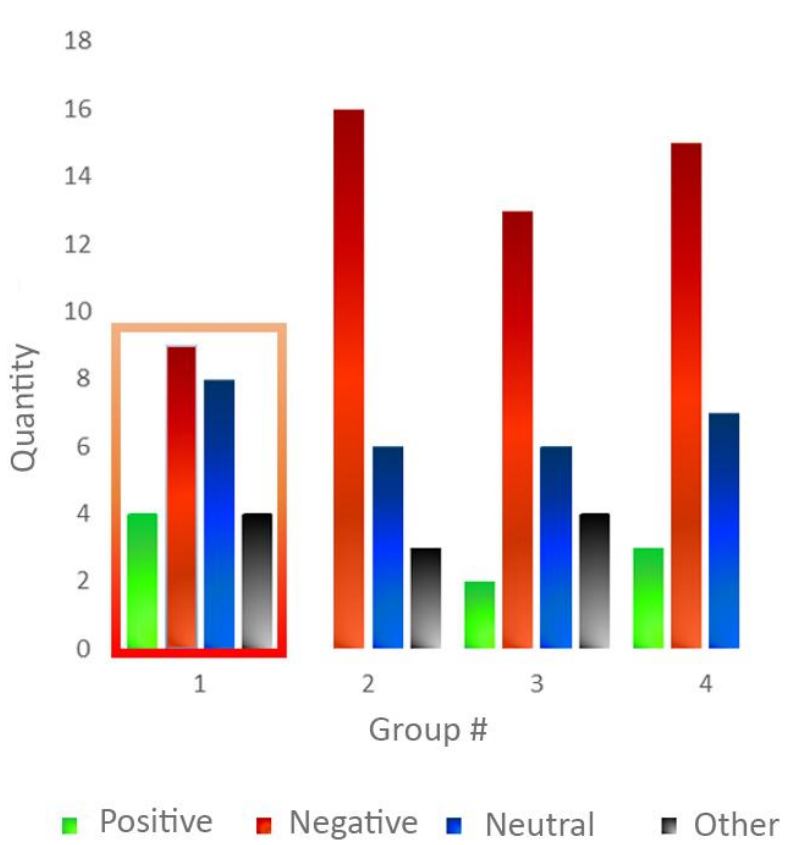

Based on the collected data, a three-level quantitative analysis of the results was carried out, where the primary measurements are carried out by the respondents and presented in shares, in the form of a frequency distribution of answers to questions (Diagrams \#2 and \#3).

\section{Diagram 2}

Summarized data of the frequency analysis of the reaction to a material with the original

video image and original sound (as a percentage of the number of respondents)

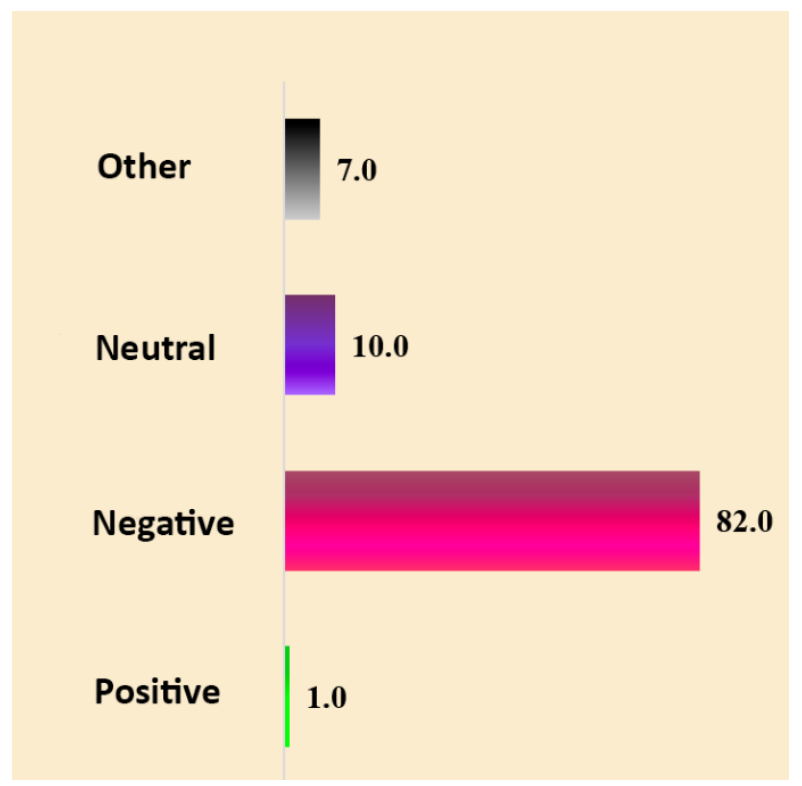

\section{Diagram 3}

Generalized data of the frequency analysis of the reaction to a piece of material with the original image, but with a modified soundtrack (as a percentage of the number of respondents)

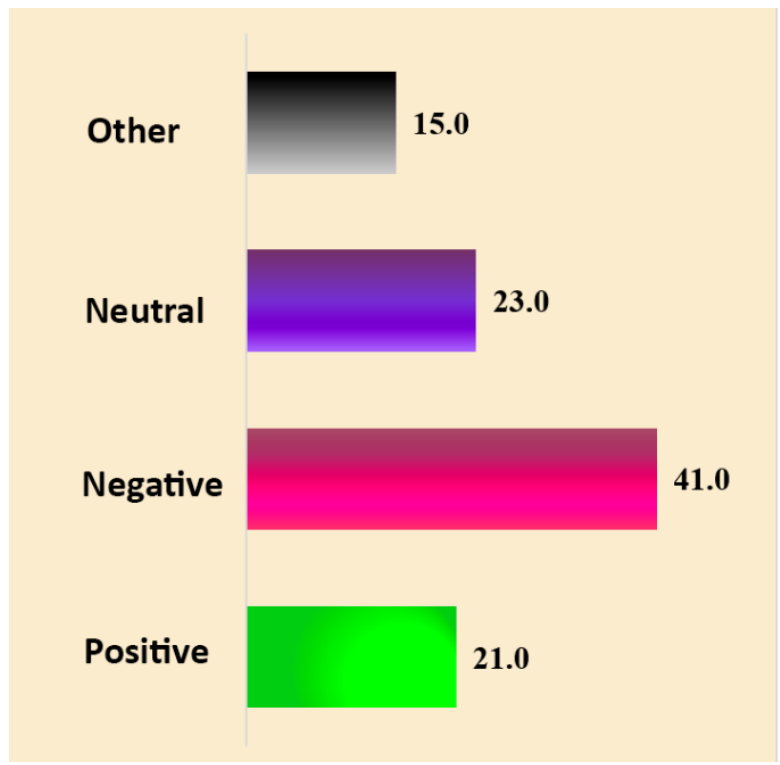

The diagrams are visualized data of primary measurements, which were carried out by the respondents, and are represented by fractions of their answers. The frequency distribution of responses has clear trends which shows the predominance of negative reactions. but that the same time, the content and direction of the reactions, whether "positive" or "negative" do not have conceptual significance within this stage of analysis, only the main trends in the distribution of responses are important. In practice it means confirmation of hypotheses put forward by the researcher and makes it possible to proceed to the next stage of measurements.

Secondary measurements were carried out by the researcher and are presented in the form of grouping procedures and indicators. The analysis of data for the entire sample set showed a high level of reaction's uniformity, but the control group showed a significant difference in one of the indicators embedded in the experimental tools. So, when we replaced the sound track, the central tendency of the control group shifted towards a positive reaction.

\section{Diagram 4}

Cross-frequency distribution of reactions of the respondents to changes in the soundtrack to the original video content in four groups 


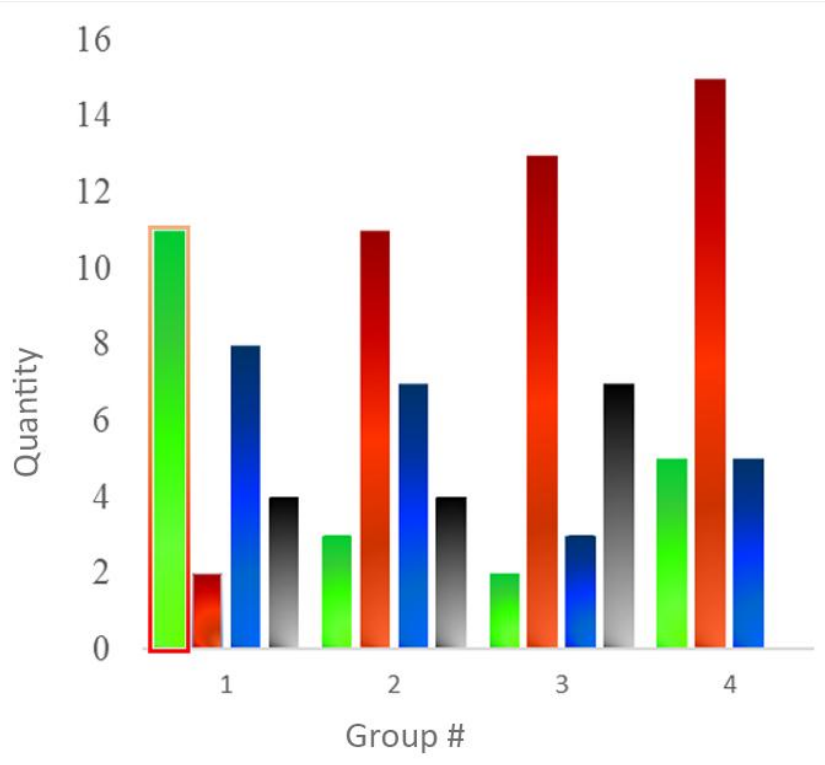

a Positive Negative Neutral Other

This indicator shows a relationship between the level of awareness of the respondent and his reactions to audiovisual content. In other words, less a consumer knows about audiovisual content, the level of his expectations is lower and, accordingly, the level of negative reactions is lower too.

Secondary measurements made it possible to identify some group trends and draw basic conclusions for a deeper analysis of the results of the research. This allowed us to start tertiary measurements carried out by the IBM SPSS Statistics 23 software, presented by two and threelevel cross-frequency analysis procedures.

The data analysis shows a connection between the awareness of respondents and the level of negative reactions at the group level. If at the level of secondary measurements, we talked only about the general trend, then we can conclude that the content of the information also matters.

We found out that knowledge of the basic principles of semiotics of sound increases the level of expectations and, accordingly, increases the level of negative response when the audiovisual material does not meet expectations. At the same time information about the conceptual idea of the work and the personality of the author has a significantly stronger impact on the final reaction of the consumer of audiovisual content (Table \#1).

However, additional studies with a higher level of representativeness are necessary to confirm these findings. It is important to note that when conducting representative researches in the future and adding questions about gender and age will significantly expand the possibilities of highlighting new useful groups.

Table 1

Conjugacy for three variables

Comb. table * Group \# * Original video without sound * Original sound without video

\begin{tabular}{|c|c|c|c|c|c|}
\hline \multirow{2}{*}{$\begin{array}{l}\text { Origin } \\
\text { al } \\
\text { sound } \\
\text { witho } \\
\text { ut } \\
\text { video }\end{array}$} & \multirow[b]{2}{*}{$\begin{array}{l}\text { Grou } \\
\text { p \# }\end{array}$} & \multicolumn{4}{|c|}{ Original video without sound } \\
\hline & & $\begin{array}{l}\text { Positi } \\
\text { ve }\end{array}$ & $\begin{array}{l}\text { Negati } \\
\text { ve }\end{array}$ & $\begin{array}{l}\text { Neutr } \\
\text { al }\end{array}$ & Other \\
\hline \multirow[t]{2}{*}{$\begin{array}{l}\text { Positiv } \\
\mathrm{e}\end{array}$} & 1 & 0 & 0 & $\begin{array}{l}50,0 \\
\%\end{array}$ & $\begin{array}{l}100,0 \\
\%\end{array}$ \\
\hline & 4 & 0 & $\begin{array}{l}100,0 \\
\%\end{array}$ & $\begin{array}{l}50,0 \\
\%\end{array}$ & 0 \\
\hline \multirow[t]{4}{*}{$\begin{array}{l}\text { Negati } \\
\text { ve }\end{array}$} & 1 & $16,7 \%$ & $15,4 \%$ & $\begin{array}{l}35,0 \\
\%\end{array}$ & $\begin{array}{l}20,0 \\
\%\end{array}$ \\
\hline & 2 & & $30,8 \%$ & $\begin{array}{l}10,0 \\
\%\end{array}$ & $\begin{array}{l}40,0 \\
\%\end{array}$ \\
\hline & 3 & $33,3 \%$ & $23,1 \%$ & $\begin{array}{l}25,0 \\
\%\end{array}$ & $\begin{array}{l}40,0 \\
\%\end{array}$ \\
\hline & 4 & $50,0 \%$ & $30,8 \%$ & $\begin{array}{l}30,0 \\
\%\end{array}$ & \\
\hline \multirow[t]{4}{*}{$\begin{array}{l}\text { Neutra } \\
1 \\
\end{array}$} & 1 & $\begin{array}{l}100,0 \\
\%\end{array}$ & $16,7 \%$ & 0 & $\begin{array}{l}50,0 \\
\% \\
\end{array}$ \\
\hline & 2 & 0 & $50,0 \%$ & $\begin{array}{l}50,0 \\
\%\end{array}$ & 0 \\
\hline & 3 & 0 & $16,7 \%$ & $\begin{array}{l}50,0 \\
\%\end{array}$ & $\begin{array}{l}50,0 \\
\%\end{array}$ \\
\hline & 4 & 0 & $16,7 \%$ & 0 & 0 \\
\hline \multirow[t]{3}{*}{ Other } & 1 & $\begin{array}{l}100,0 \\
\%\end{array}$ & $33,3 \%$ & 0 & $\begin{array}{l}33,3 \\
\%\end{array}$ \\
\hline & 2 & 0 & $16,7 \%$ & $\begin{array}{l}100,0 \\
\%\end{array}$ & $\begin{array}{l}33,3 \\
\%\end{array}$ \\
\hline & 3 & 0 & $50,0 \%$ & 0 & $\begin{array}{l}33,3 \\
\%\end{array}$ \\
\hline
\end{tabular}




\section{Conclusions}

Based on the results of this experiment, the following conclusions have been obtained:

1. A sound is one of the languages of an audiovisual product in the context of its perception by the audience as part of an integrated communication system. It has the properties of a sign and a communication system is included between the author of the work and the consumer of the audiovisual product;

2. A sound is important for the perception of audiovisual representations of a wide variety of formats;

3. There is a connection between the idea of a product and its sound realization;

4. A sound can change associations, serve as an element of interpretation of signs and semiotic connections on a deep emotional level;

5. A sound implementation, which carried out incorrectly and is not corresponding to the main idea of the product can cause a negative reaction from the end user of the audiovisual product and may lead to loss of realization of the author's artistic idea and its delivery in the original form, conceived by the author of the work;

6. An evaluation of reactions shows that correctly selected audio accompaniment can enhance the positive response from the consumer of the content.

Summing up, we would like to note that this article is one of the first steps to exploring the possibilities of applying the semiotics methods of sound in the creating of modern educational materials. At this stage, we can say that the sound accompaniment is important for achieving educational goals in conducting classes or lessons with the widespread use of audiovisual content. Further study of this topic within the framework of this article will significantly improve the quality of audiovisual content through the application of semiotics of sound.

\section{References}

[1] Parkhomenko N. A., Zolotukhin S. A. "The main approaches to the development of instructional videos in massive open online courses" Scientific notes. Electronic scientific journal of the State University of Kursk. 2018. \#2 p. 46

[2] E. G. Azimov, A. N. Shchukin. "A new dictionary of methodological terms and concepts". - Publishing house "IKAR". 2009.

[3] L.A. Karpenko, A.V. Petrovsky, M. G. Yaroshevsky "Brief psychological dictionary". - Rostov-on-Don: "PHOENIX". 1998.

[4] Khadzhimuhamedov M.K., Bokun I.M., Garipov F.R., Reshetnikov I.V. "Modern approaches to constructing a representative national territorial sample // Journal "Public Opinion. Human Rights" \#4, 2017, " IzhtimoiyFikr " p. 104 